\title{
Investment and Exchange Rate Uncertainty under Different Regimes
}

\author{
Cristiano Aguiar de Oliveira \\ Professor- Programa de Pós-Graduação em Economia Aplicada (PPGE-FURG) \\ Endereço: Avenida Itália, km 8, anexo 4 - Campus Carreiros - Rio Grande/RS - Brasil \\ CEP: 96203-900 - E-mail: cristiano.oliveira@furg.br \\ Recebido em 18 de março de 2013. Aceito em 21 de maio de 2014.
}

\begin{abstract}
This paper examines the impact of the exchange rate uncertainty on investment under different exchange rate regimes. The paper presents a theoretical model where exchange rate is a stochastic process and investment decision behaves as a Real Option. The paper evaluates the performance of a new project investment under free float, fixed and intermediate exchange rate regimes (managed float and crawling peg). The comparison among the different regimes shows that the crawling peg has advantages when compared to other regimes. The regime stability implies that less currency devaluations are necessary to stimulate investment, especially when there is a significant loss of market power in foreign markets.
\end{abstract}

\section{Keywords}

exchange rate regimes, uncertainty, investment, real options

\section{Resumo}

Este artigo estuda o impacto da incerteza a respeito da taxa de câmbio no investimento sob diferentes regimes de câmbio. O artigo apresenta um modelo teórico em que a taxa de câmbio é um processo estocástico e o investimento se comporta como uma opção real. $\mathrm{O}$ artigo avalia o desempenho de um novo projeto de investimento sob taxas de câmbio flutuante, fixa e intermediária (flutuação administrada e bandas). A comparação entre os diferentes regimes mostra que o regime de bandas cambiais possui vantagens quando comparados aos outros regimes. A estabilidade do regime implica que menores desvalorizações são necessárias para estimular o investimento, especialmente quando há uma perda significativa de poder de mercado nos mercados externos.

\section{Palavras-Chave}

regimes de câmbio, incerteza, investimento, opções reais

\section{Classificação JEL \\ C61, E22, F31}




\section{Introduction}

In the economic literature, there is the recognition that the exchange rate has a relevant role in open economies. Exchange rates influence many economic variables such as domestic prices, through the pass-through mechanism, and the product, through its impact on the balance of payments. However, some studies emphasize its importance for the explanation of other product components (Rose, 1994; Flood and Rose, 1995) and more specifically on investment (Goldberg, 1993; Darby et al., 1999; Campa and Goldberg, 1999). In theory, movements in the exchange rate have at least two direct and opposite effects on investment. Exchange rate depreciation implies an increase of the export's income and a restriction to the entrance of new competitors. On the other hand, it also implies an increase in import costs. Moreover, a movement in the exchange rate may be a source of uncertainty for agents that evaluate the viability of a new investment project. In this situation, the exchange rate volatility can be as much as or more relevant than the explanation of the investment at its nominal level (Caballero and Cobo, 1989).

Firms make new investments in order to create and take advantage of profitable opportunities. However, investment can be irreversible because the capital can be firm specific or sector specific. In general, capital goods are produced fitted to a specific firm and they probably will only be able to be used by one firm, because their sale may implicate in the revelation of a business secret. Furthermore, it would be difficult to sell an unsuccessful firm, so it will be sold at a lower value than its implantation cost, hence generating a great loss to the investor. The possibility of an unrecoverable loss makes the investment more sensitive to several risk forms, such as the uncertainty regarding good prices and input costs.

Another important aspect to be considered is that investments can be postponed. New information can bring about scenarios that can be favorable or unfavorable in the future. In both cases, it is possible to be optimal, to wait and execute the investment project later on. In the case of a favorable scenario, the postponement guarantees the exclusion of a low revenue operation period. In the adverse scenario, the waiting period can have a long duration and the investment project may not be executed (Pindyck, 1986; McDonald and Siegel, 1986; Dixit, 1989). 
So, considering that new investments are in fact rights but a not obligation to take some action in the future in an uncertain environment, the investment has characteristics of Real Options. Real Options theory potentially offers a powerful valuation tool as well as a systematic strategy framework to evaluate and structure resource investments under uncertainty (Trigeorgis, 1996; Amram and Kulatilaka, 1999; Schwartz and Trigeorgis, 2001).

The uncertainty sources can be specific of the firm, for example, its acceptance in the market, or they can be generalized and affect all the country firms, for instance, regarding uncertainty about the exchange rates. This last source of uncertainty is the main interest of this paper since, in the economic history, several countries have tried to reduce the exchange rate uncertainty, establishing explicit limits for its fluctuation or simply fixing it. This exchange rate regime change, in general, does not have the purpose of fomenting investment, but to guarantee price stability.

However, it is a matter of common sense that economic stability creates conditions for investment projects to be executed. So, there is, at this point, a theoretical gap, since there is no consolidated theory that connects the different exchange rate regimes and investment, ${ }^{1}$ in spite of the implications in real economy that the choice of exchange rate regime is one of the most relevant subjects in international economics. ${ }^{2}$ This paper presents a Real Options model for a new project investment that considers its irreversibility and the exchange rate as sources of uncertainty. The model is evaluated under the more usual exchange rate regimes: ${ }^{3}$ fixed, float and intermediate regimes, more specifically the managed float and the crawling peg.

1 Kogut and Kulatilaka (1994) developed a model that captures the option value of production switching between two country locations in the presence of volatile exchange rates. Darby et al. (1999) only analyses the impact of exchange rate uncertainty on investment under a floating regime. Böhn e Funke (2001) present a small open economy partial equilibrium model with different exchange rate regimes, but they do not use Real Options set up.

2 For reviews of the literature on the choice of exchange rate regime, see Wickham (1985), Argy (1990), Edison and Melvin (1990), Obstfeld (1995) and Frankel (1999) among others.

3 Frankel (1999) identifies nine exchange rate regimes: currency union, currency board, fixed exchange rates, adjustable peg, crawling peg, basket peg, target zone or band, managed float and freefloat. Levy-Yeyati and Sturzenegger (2005) group these regimes in four categories, with the first three corresponding to a fixed category, the next three to a crawling peg, and the last two to a dirty and a pure float. So, the paper covers all exchange rate regimes under this classification. 
Besides this introduction, the paper has two more sections. In the next section, the basic theoretical model and its extensions are presented. Its discussion is held throughout the section. At the end of the paper the main conclusions are presented.

\section{Investment Models with Different Exchange Rate Regimes}

It is very difficult to reach a consensus about the classification of exchange regimes. These regimes could simply be classified as fixed, float and intermediate (managed float and crawling peg). However, in practice, it is not so simple to implement a classification of this type. The literature shows that there is a classification publicized by the policymakers (de jure) and also the classification that the agents believe to be the true, (de facto). This distinction is necessary, since several policymakers are afraid to assume an explicit target and be susceptible to speculative attacks or to assume that the exchange rate is totally floating and, when there is a movement, in a direction that significantly affects the real economy, they cannot intervene. ${ }^{4}$ In fact, there are incentives for policymakers not to reveal the actual true regime. For the firms, the decision of investing in a long term project is not so dependent on policymakers public announcements but will be based on their perception of which regime is being adopted; in other words, de facto classification is what matters.

A regime may be considered fixed if there is an explicit target for the nominal exchange rate and the monetary authority accomplishes explicit interventions to reach this target. In the free (pure) float regime there is no intervention form and the nominal exchange rate is able to assume any value between zero and infinite. Intermediate regimes can be of two types. The first is called "managed" (dirty) float. In this regime there is no explicit target for the nominal exchange rate, but the firms know about the existence of limits. These limits can be inferior (limiting valorizations) or superior (limiting depreciations) or both. In the latter case, this regime would have a similar behavior to the second type of intermediate regime studied in the paper, the crawling peg regime. The main difference between these regimes is that the crawling peg makes its limits explicit.

4 Calvo and Reinhart (2002) call it "fear of floating". 
However, from the practical point of view, what matters for the firms is a de facto regime and being this way, the two regimes are identical. $^{5}$

The basic model is composed by one good, produced by a representative potential entrant monopolist firm, which will be established in two different markets, a domestic market and a foreign market, with the capacity to discriminate prices. That is, the goods sold in one market cannot be sold in the other. The firm will decide if it invests or not in a new investment project where the cost is given by I. ${ }^{6}$ This cost is fixed and irreversible. Once implemented, will have an income (profit) for an infinite period. Its monopoly power in each market is a function of each market demand. These are given in their inverted form by:

$$
\begin{aligned}
& P_{d}=Q_{d}^{-\frac{1}{\varepsilon_{d}}} \\
& P_{f}=Q_{f}^{-\frac{1}{\varepsilon_{f}}}
\end{aligned}
$$

Where $d$ denotes the domestic market and $f$ denotes the foreign market. $P$ represents the good's price, $Q$ represents the demanded quantity and $\varepsilon$ is the demand elasticity-price.

The good sold in the external market is paid for with foreign currency; however, it is converted into the domestic currency by a nominal exchange rate given by $E$. There are no transport costs. So, the monopolist's profit, when the project is implemented, in each period $t$ is given by:

$$
\pi\left(P_{d}, P_{f}, Q_{d}, Q_{f}, E\right)=P_{d} Q_{d}+P_{f} Q_{f} E-w\left(Q_{d}+Q_{f}\right)
$$

\footnotetext{
5 It should be emphasized that the investment behavior is analyzed under these regimes; however, the influence of uncertainty, regarding the adopted regime, is not studied. It is assumed that the agents are capable of distinguishing which regime is being adopted and, therefore, there is only uncertainty about the exchange rate proper.

6 The firm is not yet established, so it is not a new capacity or expansion decision as proposed by Trigeorgis and Mason (1987), Pindyck (1988), Dixit (1989) and Dixit (1992).
} 
Where $w$ is the marginal cost. It does not depend on the exchange rate because the good is only produced using local input. The monopolist's profit is maximized at each market when:

$$
\begin{aligned}
& Q_{d}^{*}=\left(\frac{1-\frac{1}{\varepsilon_{d}}}{w}\right)^{\varepsilon_{d}} \\
& Q_{f}^{*}=\left[\frac{\left(1-\frac{1}{\varepsilon_{f}}\right)}{w} E\right]^{\varepsilon_{f}}
\end{aligned}
$$

So, the monopolist's profit will be:

$$
\pi_{M}^{*}\left(P_{d}, P_{f}, Q_{d}, Q_{f}, E\right)=A+B E^{\varepsilon_{f}}
$$

Where:

$$
\begin{aligned}
& A=\frac{1}{\varepsilon_{d}}\left(\frac{1-\frac{1}{\varepsilon_{d}}}{w}\right)^{\varepsilon_{d}-1} \\
& B=\frac{1}{\varepsilon_{f}}\left(\frac{1-\frac{1}{\varepsilon_{f}}}{w}\right)^{\varepsilon_{f}-1}
\end{aligned}
$$

The Equation (6) establishes that the monopolist's profit can be decomposed into two parts. The first term given by $A$ is the profit obtained in the domestic market and the second term given by $B E^{\varepsilon_{f}}$ is the profit obtained in the foreign market. This representative firm should analyze the decision of investing in a new project under the different exchange regimes.

\subsection{Fixed Exchange Rate}

In the fixed exchange rate regime there is not stochastic components in the model. However, the monopolist firm has an exchange rate that triggers the investment independently from the fixed exchange rate. 
Proposition 1: Consider that the monopolist firm obtains in each period t a profit given by (6), so the monopolist's dynamic problem is $\max \int_{0}^{\infty} \pi_{M} e^{-\rho t} d t$. Then, the solution for this non stochastic optimization problem is given by $E^{*}=\left[\frac{\rho}{B}\left(I-\frac{A}{\rho}\right)\right]^{\frac{1}{\varepsilon_{f}}}>0$.

Proof: Appendix 5.1

Where the nominal exchange rate that makes investment viable, $E^{*}$, is greater than zero if $B>0$ and $A<\rho I$. These conditions mean that there are profits in the foreign market and that the profit share obtained in the domestic market is not enough to cover the investment's present value in each period $t$. Otherwise, the project would be executed independently of the nominal exchange rate level. So, the main result of this model is, that under a fixed exchange regime, the monopolist firm will invest if $\bar{E}>E^{*}$. It means that under this regime the monopolist firm will invest, if the present value of the project's future return is greater than its cost, just as predicted by the net present value rule (Jorgenson, 1963).

An adjacent conclusion is that under a fixed exchange regime many investment projects are abandoned because they are not viable under the established exchange rate $(\bar{E})$ In other words, the exchange rate fixation only implies that investments are compatible with the established rate.,

Even though this regime is adopted in many situations to solve uncertainty and/or high volatility problems, this policy choice has several implications. In the first place, it is only effective to eliminate uncertainty if the policymaker has the capacity to maintain it during a long period. Otherwise, the expectation of a possible future depreciation will generate, as much as or more uncertainty, than in a free float regime. This credibility problem had already been presented by Kydland and Prescott's (1977) original work and then, the analysis was extended to the best exchange rate regime in the context of an open economy. It evaluates the cost-benefit of abandoning this exchange rate instrument. Economic agents realize that there may be future situations in which a change in the exchange rate would be optimal for policymakers and, therefore, the incentive arises for them to renege on their commitment. The credibility problem can only be solved if the authorities, in playing their game against the 
other economic agents, are really able to convince agents that their only objective is the maintenance of fixed exchange rates, regardless of the costs induced by this choice of strategy. Nonetheless, exiting a fixed exchange rate regime, may also be costly since, in general, it is followed by strong depreciations ${ }^{7}$. In general, the main conclusion of the literature is that an exchange rate policy should be as consistent as possible ${ }^{8}$ to solve uncertainty problems.

\subsection{Free Float}

Consider now that the profit given by (6) is composed by deterministic and stochastic components. It is assumed that the nominal exchange rate floats freely and that it is a stochastic process that follows a geometric Brownian movement. The other parameters in the model are assumed to be deterministic. Therefore, the nominal exchange rate is the only fact responsible for the uncertainty regarding the future profits. Under these conditions, the monopolist's dynamic problem will be:

$$
\begin{aligned}
\operatorname{Max} & \mathbb{E} \int_{0}^{\infty} \pi_{M} e^{-\rho t} d t \\
\text { s.t. } & \frac{d E}{E}=\mu d t+\sigma d z
\end{aligned}
$$

Where $\rho$ is a discount rate and $z$ represents Wiener's process where $d z=\xi_{t} \sqrt{d t}$ and $\xi_{t} \sim N(0,1)$. The parameter $\mu$ represents the positive or negative increments on the nominal exchange rate over time and $\sigma$ the volatility of these increments. It should be noted that the process variance grows linearly over time, since $\operatorname{Var}(d z)=d t$ and that the nominal exchange rate follows a log-normal distribution.

Proposition 2: If the monopolist problem is given by (7), then, the exchange rate critical value is $E^{*}=\left[\frac{\Delta \lambda_{1}}{B\left(\varepsilon_{f}-\lambda_{1}\right)}\left(\frac{A}{\rho}-I\right)\right]^{\frac{1}{\varepsilon_{f}}}$.

Proof: Appendix 5.2

7 Krugman (1979) and Flood and Garber (1984) are the classical references of the currency crisis literature.

8 In this case, consistency is related to an exchange rate closely associated to fundamentals as in Krugman (1989). 
Where $\lambda_{1}$ is the positive root from the indicial equation. The condition $\lambda_{1}>\varepsilon_{f}>0$ is necessary to have $E^{*}$ greater than zero and to give economic sense to the problem, since $A<\rho I$. This last condition means that the profit share obtained in the domestic market is not enough to cover the investment's present value in each period $t$. Otherwise the project would be executed independently of the nominal exchange rate level.

Note that the critical value $E^{*}$ under the free float regime is related to model parameters in a more complex way than it is under fixed exchange regime. Under the free float regime, investments may be viable due to the expectation of future depreciations, even if at present, the exchange rate is not favorable. Fixing the exchange rate, this expectation disappears. Besides, the firm should have an increase on their profits to compensate the uncertainty due the nominal exchange rate.

Corollary 1: If $\frac{\partial \lambda_{1}}{\partial \sigma}>0$, the firm profit present value should be greater than the invested value.

Proof: Appendix 5.3

The source of a profit increase can be a currency devaluation, since the optimal investment critical value $\left(E^{*}\right)$ rises when this occurs. This result can be better observed in a numerical example with $\rho=0.04, I=50, \varepsilon_{f}=\varepsilon_{d}=1.1, w=3$. The results can be seen in figure 1 .

Figure 1 shows that when the exchange rate volatility rises from $5 \%$ to $15 \%$, the critical exchange rate that makes the investment viable grows from 2.05 to 2.92 . This means that a depreciation of $42.47 \%$ is needed, in the exchange rate, to make the option of investing optimal once again. This impact is larger when the depreciation trend is increased. An increase in the trend from 2\% to 3\% makes a depreciation of $50.89 \%$ necessary. 


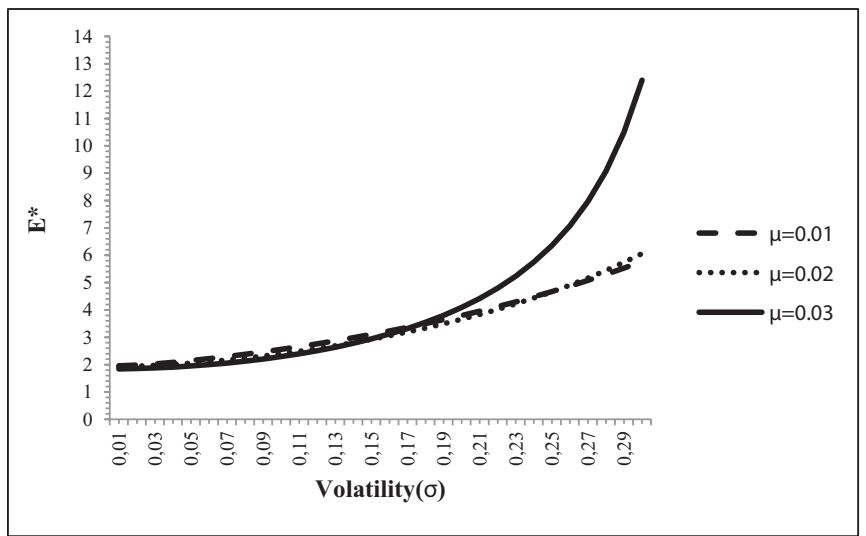

Figure 1 Critical value $\left(E^{*}\right)$ as a function of $\sigma$ and $\mu$

Therefore, under a free float regime, the uncertainty regarding the exchange rate is capable of reducing the investment. ${ }^{9}$ This impact is larger the greater the depreciation trend. Thus, policies that seek to reduce the negative impact of uncertainty on investment can have a different effect from that expected, since the impact of uncertainty also changes when the exchange rate trend is altered. ${ }^{10}$ These results reproduce Krugman's (1989) ideas. According to the author, in a high uncertainty environment, with volatile exchange rates, the firms have incentives to adopt a "wait and see" behavior, regarding investments and negotiations with foreign markets. Huizinga (1993) and Bell and Campa (1997) give empirical support to this result. The authors found a negative relationship between the exchange rate volatility and the investment of European and American firms, respectively.

There are, therefore, advantages and disadvantages regarding investment in both regimes. In practice, policymakers have been seen to adopt intermediate regimes, such as managed float and crawling peg.

9 This result was expected once the literature on irreversible investment has already shown that uncertainty harms investment spending by risk-neutral firms, if the cost of reducing the capital stock exceeds the upward adjustment cost and if firms operate under imperfect competition.

${ }^{10}$ Darby et al. (1999) also commented the role of exchange rate trends (misalignments as they called it) in the investment decision, but the authors did not infer any conclusion about it in the model. Goldberg (1993) only analyzes the impact of exchange rate volatility on investment but did not consider the impact of trend changes. 


\subsection{Exchange Rate Regime with Interventions (Managed Float)}

In this regime, there is not an explicit goal for the nominal exchange rate, but the monetary authority intervenes, whenever it crosses a certain value limit. Interventions occur only at boundaries. Limits can be inferior or superior. Supposing that firms are capable of identifying these limits and that these can only exist, initially, in one direction. ${ }^{11}$ Initially, let us consider the existence of a superior (upper) limit given by $E_{H}$. The active firm's value now does not more include the restriction on overvaluations to rule out speculative bubbles, since the function has a superior limit.

Proposition 3: If a monopolistic firm faces an upper limit $E_{h}$, then the critical value is $E_{h}^{*}=\left[\frac{\Delta \lambda_{1}}{B\left(\varepsilon_{f}-\lambda_{1}\right)}\left(\frac{A}{\rho}-I\right)\right]^{\frac{1}{\varepsilon_{f}}}$ and this value is identical to $E^{*}$. Proof: Appendix 5.4

The explanation for this result is that, in this case, the reduction in the active firm value is equal to the reduction in the inactive firm value. In other words, when the future profits are reduced, the superior limit also is reduced, in the same magnitude as the opportunity cost of the investing option. As a result, in a managed float regime, with an exchange rate superior limit, there are no distortions in the agents' decision. Another interesting point is that the critical value does not depend of the limit value established, even though it affects the firm's value directly. In this model, the firm's value is lower and, consequently, the firm loses money when a superior limit for the exchange rate is established. The remaining model interpretations are similar to the free float regime model; however, it changes when there is an inferior limit for the exchange rate.

Proposition 4: If a monopolistic firm faces a lower limit $E_{l}$, then the critical value is $E_{l}^{*}=\left[\frac{\Delta \lambda_{2}}{B\left(\varepsilon_{f}+\lambda_{2}\right)}\left(I-\frac{A}{\rho}\right)\right]^{\frac{1}{\varepsilon_{f}}}$.

Proof: Appendix 5.5

11 This assumption will be relaxed in the next section when crawling pegs will be studied. 
Under an exchange rate lower limit, the increase in the firm's value is superior to the increase in the opportunity costs. It means to say that, under an exchange regime, with managed float, the establishment of an inferior limit for the exchange rate reduces the possibility of losses, with the foreign market making the exports and, consequently, the investment is viable, even if the nominal exchange rate is at a low level. This result is due to the $E_{l}^{*}$ dependence from the negative root of the indicial equation given by $\lambda_{2}$. It is possible to show that, the expression that multiplies the difference between the project value and the present value of future profits in the domestic market is always lower when there is an inferior limit. It will be seen more clearly further ahead in a numerical example.

\subsection{Crawling Peg Regime}

In the previous subsection we have seen what happens when superior and inferior limits, for the nominal exchange rate, are adopted. In the case of a superior limit, the active firm's value is reduced while, in the case of an inferior limit, it is increased. But, what happens when both are adopted simultaneously in an explicit form? This is the case of a crawling peg regime. It should be pointed out that, in this regime, if the bands are too narrow it has few differences regarding a fixed exchange rate regime. However, it is assumed that these bands are wide enough so that there is some space for fluctuation. Again, the interventions occur only at boundaries and else the possibility of intra marginal interventions within the band is excluded.

Under these assumptions no analytical solution to $E_{c p}^{*}$, the critical value for the nominal exchange under a crawling peg regime, may be obtained. Since there are two non linear equations with two unknown values that remain to determine two unknowns. As it can be seen in the appendix 5.6, the first difference of this model with a free float model is that the active firm's value is now dependent on the band limits. This dependence from the band limits can be seen more clearly in a numerical example with $\rho=0.04, \mu=0.02, I=50$, $\varepsilon_{f}=\varepsilon_{d}=1.1, w=3, \sigma=0.1$ and $E_{L}=1$ in Figure 2. It shows that the critical value for the nominal exchange under a crawling peg regime which calls the investment option is optimal decreases when the bandwidth increases. 
This result is explained by the fact that a wider bandwidth implies larger profit expectations due to possible exchange rate depreciations.

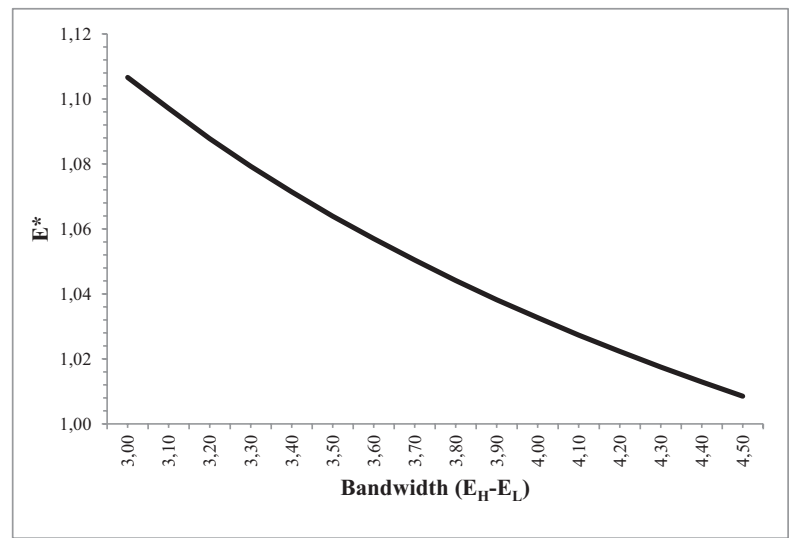

Figure 2 - Critical value $\left(E_{c p}^{*}\right)$ as a function of the exchange rate superior and inferior limit.

Another model result is that, the crawling peg critical value will always be between the critical value for an inferior limit and a superior limit (same value as the free float regime). It is possible to observe this in a simulation using the same parameter values. The results are in Figure 3. It shows the impact of an increase in the uncertainty (volatility) under different exchange regimes.

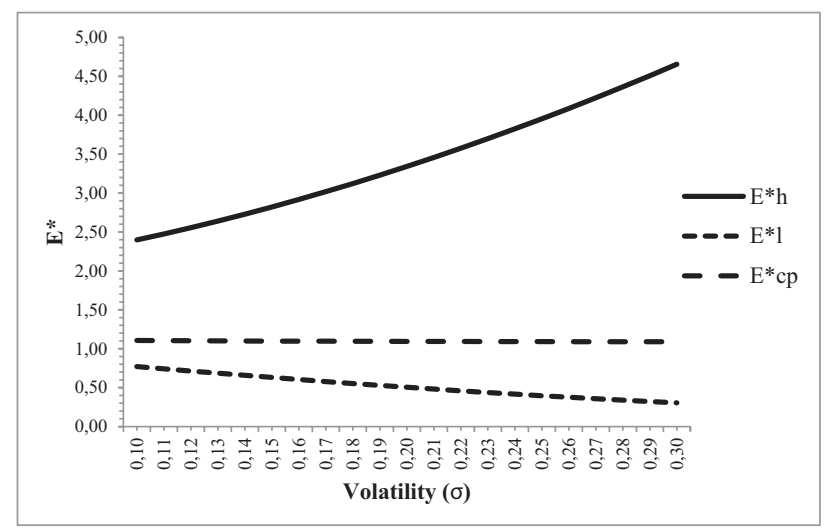

Figure 3 - Critical value $\left(E^{*}\right)$ as a function of $\sigma$ and the exchange rate limits. 
Figure 3 shows that the impact of the exchange rate volatility is different for the two limit types. In the model with an inferior limit, the increase in the volatility reduces the critical value that makes the investment option optimal. It occurs due to its $\lambda_{2}$ dependence, since $\frac{\partial \lambda_{2}}{\partial \sigma}<0$. This result may be not intuitive, but a possible explanation would be the fact that the inferior limit reduces the possibility for valorizations to occur. Thus, an increase of the volatility will be noticed by the firms as an increase in the possibility for big future depreciations to occur and, hence, increasing the active firm's value and reducing the critical value for the investment execution. The same occurs with the crawling peg regime, but the model is less sensible to volatility increase than other exchange rate regimes. Figure 3 shows that the critical value almost does not change as the volatility increases. Consequently, the crawling peg regime favors investment because it implies on smaller and more stable critical values. In fact, it is an important characteristic of this regime, because the same occurs when other model parameters are analyzed. It is the case of a change in the foreign market demand elasticity.

Campa and Goldberg (1999) show that the effects of the exchange rate on the firm's investments are inversely related to its mark-up ratios. Investment in a highly competitive market, with low mark-up ratios is more dependent on exchange rate movements. Analyzing two-digit manufacturing sectors in the United States, the United Kingdom, Canada, and Japan, they find that, across countries, exchange rates tend to have insignificant effects on investment rates in high mark-up sectors. However, investment responsiveness to exchange rates is fairly strong in low mark-up sectors.

The model presented here reproduces authors' model and results, but it goes further. Lower mark-up (high demand elasticity) firms need a higher exchange rate critical value to trigger investment (as in Campa and Goldberg, 1999), but in the crawling peg regime this difference is smaller than in a free float regime. In other words, in a free float regime, low competitive firms need greater exchange rate devaluations than in a crawling peg to keep the investment projects of these firms viable. This can be seen in Figure 4. As a result, some type of control over the exchange rate would be adequate, when local goods have more competitive external markets. Ghosh et al. (1997) show that the investment is about 2\% of the GDP - larger in regimes that use some type of intervention than in float regimes 
and that this difference is still big when appraised for countries with high income.

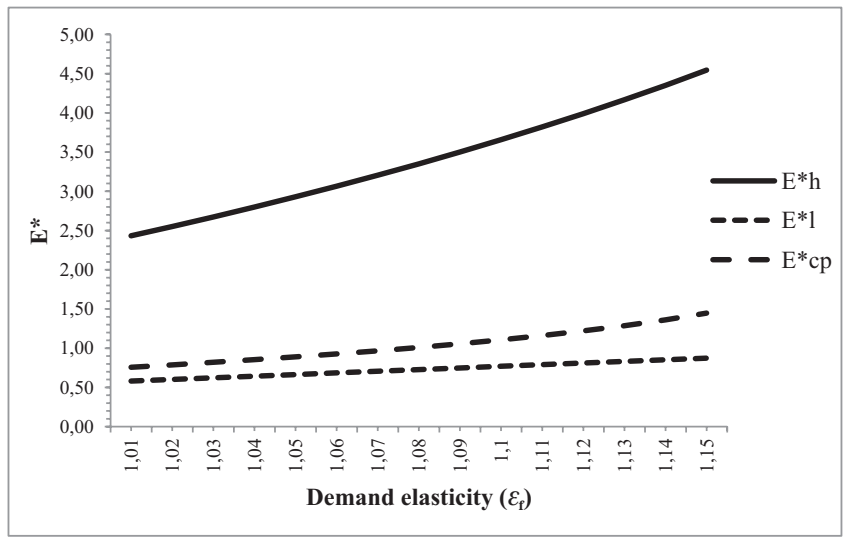

Figure 4 Critical value $\left(E^{*}\right)$ as a function of the foreign market demand elasticity under the different exchange rate regimes.

It should be emphasized that this analysis is limited to the impact of the exchange rate on the investment and it does not consider the impact that this control would have on other economic variables, such as currency reserves.

\section{Conclusions}

This paper, based on the investment model proposed by Real Options theory presented a model to study investment behavior under different exchange regimes. The paper contributes to the debate regarding investment when it detaches the importance of uncertainty, since in this theme, it seems to have an excessive emphasis on the interest rates policy, when actually, the economic stability, is more relevant for investment decisions, especially in underdeveloped economies. The models presented show that, the larger the exchange rate volatility the smaller the investment. However, it is important to state that the proposed theoretical model does not make any aggregation and, therefore, its interpretation in macroeconomics should be cautious. Nonetheless, the main results are in accordance with the empirical evidence presented in the literature. 
The paper concludes that investment is greater in a regime that has some exchange rate control, such as the crawling peg regime. Moreover, this regime presents a larger capacity to soften the impact on the investment of changes in other parameters, such as a market power loss of exporter firms. At least, this advantage in relation to the free float regime is a contribution of the present paper, since this aspect had not been addressed in the previous literature. However, it should be clear that these conclusions do not consider the effects of the regime type adoption on the remaining economic variables, its condition of being sustained for long periods and their impact in the monetary policy. The policymakers' role is to evaluate the advantages and disadvantages of each regime and to adopt the regime considered most appropriate.

Finally, it is evident that more theoretical and empirical studies are needed to evaluate the impact of the different exchange regimes on investment. From a theoretical point of view, there is the need to build models that consider the effects of the exchange rates, not only in the goods prices, but also in the input costs and in the execution costs of the investment project. Another possibility is the inclusion of new external markets, since there is evidence that many firms try to export to several countries and/or to own several plants, exactly for the purpose of reducing exchange rate risks.

\section{References}

AMRAM, M.; KULATILAKA, N. (1999) Real options: Managing strategic investment in an uncertain World. Boston: Harvard Business School Press.

ARGY, V. (1990) "Choice of exchange rate regime for a smaller economy: A survey of some key issues" in Choosing an Exchange Rate Regime: The Challenge for Smaller Industrial Countries, Victor Argy and Paul De Grauwe (eds), International Monetary Fund, 6-81.

BÖHM, H.; Funke, Michael (2001) "Does the nominal exchange rate regime matter for investment?" CESifo Working Paper Series $\mathrm{N}^{\mathrm{o}} 578$.

CABALlERO, R. J.; CORBO, V. (1989) "How does uncertainty about the real exchange rate affect exports?” Policy Research Working Paper Series. N ${ }^{\circ} 221$. The World Bank.

CALVO, G.; REINHART, C. (2002) “Fear of floating” The Quarterly Journal of Economics, 117 (2), 379-408.

CAMPA, J. M. (1993) "Entry by foreign firms in the United States under exchange-rate uncertainty" Review of Economics and Statistics, 75(4), 614-622.

; GOLDBERG, L. S. (1999) "Investment, pass-through, and exchange rates: A cross-country comparison" International Economic Review, 40(2), 287-314. 
DARBY, J. H.; HALLETT, R. A.; Ireland, Jonathan.; Piscatelli, Laura (1999) "The impact of exchange rate uncertainty on the level of investment" Economic Journal, 109, 55-67.

DIXIT,A. K. (1989) “Entry and exit decisions under uncertainty” Journal of Political Economy, 97, 620-638. (1992) "Investment and hysteresis" Journal of Economic Perspectives, 6(1), 107-132. ; PINDYCK, R. S. (1994) Investment under Uncertainty. Princeton: Princeton University Press.

FLOOD, R. P.; GARBER, P. M. (1984) "Collapsing exchange-rate regimes: some linear examples.” Journal of International Economics, 17, 1-13.

; ROSE, A. K. (1995) "Fixing exchange rates: A virtual quest for fundamentals" Journal of Monetary Economics, 36 (1), 3-37.

FRANKEL, J. (1999) "No single currency regime is right for all countries or at all times" NBER Working Paper 7338.

GOLDBERG, L. S. (1993) "Exchange rates and investment in United States industry" Review of Economics and Statistics, 75(4), 575-589.

GHOSH, A-M.; GULDE, Anne-Marie; OSTRY, J.; WOLF, H. (1997) "Does the nominal exchange rate regime matter?" NBER Working Paper $N^{\circ} .5874$.

HUIZINGA, J. (1993) "Inflation uncertainty, relative price uncertainty, and investment in US manufacturing" Journal of Money, Credit and Banking, 25, 521-54.

JORGENSON, D. (1963) “Capital theory and investment behavior" American Economic Review, 53, 247-259.

KOGUT, B., KULATILAKA, N. (1994) "Options thinking and platform investments: Investing in opportunity" California Management Review, 36(2), 52-71.

KRUGMAN, P. R. (1979) "Model of Balance-of-Payments Crises" Journal of Money, Credit and Banking, 11, 311-325.

(1989) Exchange Rate Instability. Cambridge: MIT Press.

KYDLAND, F.; PRESCOTT, E. (1977) "Rules Rather than Discretion: The Inconsistency of Optimal Plans" Journal of Political Economy, 85, 473-492.

LEVY-YEYATI, E.; STURZENEGGER, F. (2005), "Classifying exchange rate regimes: deeds versus words" European Economic Review, 49, 1603-35.

MCDONALD, R.; SIEGEL, D. R. (1986) “The Value of Waiting to Invest” Quarterly Journal of Economics, 101(4), 707-27.

OBSTFELD, M. (1995) "International Currency Experience: New Lessons and Lessons Relearned" Brookings Papers on Economic Activity, 1, 119-211.

PINDYCK, R. S. (1986) "Capital risk and models of investment behavior", mimeo, Sloan School of Management, MIT.

(1998) "Irreversible investment, capacity choice, and value of the firm" American Economic Review, 78(5), 969-985.

(1991) “Irreversibility, uncertainty and investment” Journal of Economic Literature, 29, 1110-48.

SCHWARTZ, E. S.; TRIGEORGIS, L. (2001) Real options and investment under uncertainty: classical readings and recent contributions. Cambridge: MIT Press.

ROSE, A. K. (1994) “Are Exchange Rates Macroeconomic Phenomena?" Federal Reserve Bank of San Francisco Economic Review, 1, 19-30.

TRIGEORGIS, L. (1996) Real options: Managerial flexibility and strategy in resource allocation. Cambridge: MIT Press.

TRIGEORGIS, L.; MASON, S. P. (1987) “Valuing Managerial Flexibility Midland” Corporate Finance Journal, 2, 14-21.

WICKHAM, P. (1985) "Choice of Exchange Rate Regime in Developing Countries: A Survey of the Literature" Staff Papers, International Monetary Fund, 32, 248-88. 


\section{Appendix}

\section{Proof of Proposition 1}

Under a fixed exchange rate regime, the option to invest will be optimal if $\int_{0}^{\infty} \pi_{M} e^{-\rho t} d t=I$, so:

$$
\frac{\pi_{M}}{\rho}=I
$$

Substituting this expression in (6) and solving to E gives:

$$
E^{*}=\left[\frac{\rho}{B}\left(I-\frac{A}{\rho}\right)\right]^{\frac{1}{\varepsilon_{f}}}
$$

\section{Proof of Proposition 2}

The option of investing is evaluated considering the value of the project once it is implemented (active value of the firm) and the opportunity cost of the project when it is not implemented (inactive value of the firm). The active value of the firm is given by the optimality condition of Bellman's equation:

$$
\rho F(E) d t=\mathbb{E}(d F)+\pi_{M}^{*} d t
$$

Where $F(E)$ represents the value of the option to invest. This condition determines that the project expected total return (left side) should be equal to the capital gain (first term right) added to the instantaneous dividends flow (second term right). To obtain $\mathbb{E}(d F)$ the Itô's lemma is used and the expectation operator is applied. Substituting this expression and (6) in (7) gives:

$$
\frac{\sigma^{2}}{2} E^{2} F^{\prime \prime}(E)+\mu E F^{\prime}(E)-\rho F(E)+A+B E^{\varepsilon_{f}}=0
$$

It is a non-homogeneous ordinary differential equation. Its solution is composed by a homogeneous solution and a particular one. The particular solution can be obtained by the uncertain coefficients method. Conjecturing a solution with the following form:

$$
F(E)_{P}=c_{1}+c_{2} E^{\varepsilon_{f}}
$$


Substituting this possible solution in (A.4) the following constant values are obtained:

$$
c_{1}=\frac{A}{\rho} \text { and } c_{2}=\frac{B}{\Delta}
$$

Where $\Delta=\rho-\mu \varepsilon_{f}-\frac{\sigma^{2}}{2} \varepsilon_{f}\left(\varepsilon_{f}-1\right)$. Thus, the particular solution will be:

$$
F(E)_{P}=\frac{A}{\rho}+\frac{B}{\Delta} E^{\varepsilon_{f}}
$$

The homogeneous solution can be obtained in the potencies form using $\mathrm{E}^{\lambda}$. It results in an indicial equation with two real different roots with different signs. In other way, this result implies that:

$$
F(E)_{H}=k_{1} E^{\lambda_{1}}+k_{2} E^{-\lambda_{2}}
$$

Where $\lambda_{1}$ and $\lambda_{2}>0, k_{1}$ and $k_{2}$ are constants to be determined. However, this problem will make economic sense only if the possibility of speculative bubbles does not exist. ${ }^{12}$ Speculative bubbles may be ruled out evoking "no overvaluations" and $F(0)=0$ conditions. The former implies that it is not possible to obtain gains selling the project for a value greater than its fundamentals, so it is necessary to set $k_{1}=0$ to avoid it. The latter implies that $k_{2}=0$ is required since the negative power of $E$ goes to infinity as $E$ goes to zero and goes to zero as E goes to infinity, but it does not make economic sense since a devaluation should increase the active firm value due to sales revenue in the foreign market. Under these conditions, the active firm value will be determined only by the particular solution (fundamentals). ${ }^{13}$

The inactive firm value does not have dividends, since the project has not been implemented yet. It is composed by the opportunity cost and by the expected project valorization. In this case, the Bellman equation will be:

$$
\rho F_{0}(E) d t=\mathbb{E}(d F)
$$

\footnotetext{
${ }^{12}$ Equation (A.6) represents the fundamental components of the project's value, while equation (A.7) represents the speculative components. The speculative components allow the project value to be greater than its fundamentals, thus it is possible to buy it and resell it later with a capital gain.

13 These conditions are only valid if there is not option to abandon.
} 
Using the same procedures used before, the expression for the inactive firm value will be:

$$
\frac{\sigma^{2}}{2} E^{2} F_{0}{ }^{\prime \prime}(E)+\mu E F_{0}^{\prime}(E)-\rho F_{0}(E)=0
$$

This homogeneous ordinary differential equation has the form of Cauchy-Euler, and its solution can be obtained in the potency form. Its indicial equation also has two different real roots with different signs and thus, just as in the previous problem, the negative root is eliminated because $F_{0}(0)=0$ condition. When $E$ goes to zero the inactive firm value goes to infinity, but it does not make economic sense because if $E$ is equal to zero there is no external market, so there is no opportunity cost. Under these conditions, the solution will be given by:

$$
F_{0}(E)=c_{1} E^{\lambda_{1}}
$$

Where $c_{1}$ is a constant to be determined and $\lambda_{1}=\frac{1}{2}-\frac{\mu}{\sigma^{2}}+\left[\left(\frac{\mu}{\sigma^{2}}-\frac{1}{2}\right)+{ }_{\sigma^{2}}^{2 \rho}\right]^{1 / 2}>1^{14}$. To obtain the constant value some frontier conditions are used:

$$
\begin{aligned}
& F_{0}\left(E^{*}\right)=F\left(E^{*}\right)-I \\
& F_{0}{ }^{\prime}\left(E^{*}\right)=F^{\prime}\left(E^{*}\right)
\end{aligned}
$$

Where $E^{*}$ represents the critical value of the nominal exchange rate that makes the option of executing the project optimal. The first condition establishes that the value of the option should be the same as the liquid value obtained when exercising it (value matching condition). The second condition establishes that these values should be tangent at the point where it is optimal to call the option (smooth -pasting condition). Using these functional forms, we have a system with two equations and two unknowns $\left(c_{1}\right.$ and $\left.E^{*}\right)$ :

$$
\begin{aligned}
& c_{1} E^{* \lambda_{1}}=\frac{A}{\rho}+\frac{B E^{* \varepsilon_{f}}}{\Delta}-I \\
& \lambda_{1} c_{1} E^{* \lambda_{1}-1}=\frac{\varepsilon_{f} B E^{* \varepsilon_{f}-1}}{\Delta}
\end{aligned}
$$

${ }^{14}$ See Dixit and Pindyck (1994), p. 142. 
This system has the following solutions:

$$
\begin{aligned}
& E^{*}=\left[\frac{\Delta \lambda_{1}}{B\left(\varepsilon_{f}-\lambda_{1}\right)}\left(\frac{A}{\rho}-I\right)\right]^{\frac{1}{\varepsilon_{f}}} \\
& c_{1}=\left(\frac{\varepsilon_{f}}{\varepsilon_{f}-\lambda_{1}}\right)\left(\frac{A}{\rho}-I\right) E^{*-\lambda_{1}}
\end{aligned}
$$

\section{Proof of Corollary 1}

It can be proved by substituting (A.12) in (A.6), so the liquid active firm value will be:

$$
F\left(E^{*}\right)_{\text {liquid }}=\left(\frac{\lambda_{1}}{\lambda_{1}-\varepsilon_{f}}\right) I
$$

Where the expression under brackets multiplying $I$ is greater than one, since $\lambda_{1}>\varepsilon_{f}>1$. This result is a consequence of the inclusion of uncertainty about the nominal exchange rate in the model. So, the active firm liquid value should be incremented to cover the project value.

\section{Proof of Proposition 3}

When the monopolist faces an upper limit, the active firm value will be given by: ${ }^{15}$

$$
F(E)=k_{1} E^{\lambda_{1}}+\frac{A}{\rho}+\frac{B}{\Delta} E^{\varepsilon_{f}}
$$

Where $\lambda_{1}$ is the positive root of the indicial equation and $k_{1}$ is a constant to be determinated. In this case, a new restriction should be added, since there is one more constant to be determined. To obtain this constant, let us suppose that the superior limit is like a reflection barrier to a firm's value such that $F^{\prime}\left(E_{H}\right)=0$. Using this restriction in (A.14), the constant will be given by:

$k_{1}=-\left(\frac{B \varepsilon_{f} E_{H}^{\varepsilon_{f}-\lambda_{1}}}{\Delta \lambda_{1}}\right)<0$

15 Note that this active firm value allows deviations from fundamentals. 
Substituting (A.15) in (A.14) it is possible to observe that the firm value is lower than the value without a superior limit, since the constant $k_{1}$ is negative. This result is rather intuitive, since the superior limit is a restriction to future profits and profits grow when the exchange rate devaluates. The active firm value with a superior limit in the exchange rate will be given by:

$$
F(E)=-\left(\frac{B \varepsilon_{f} E_{H}^{\varepsilon_{f}-\lambda_{1}}}{\Delta \lambda_{1}}\right) E^{\lambda_{1}}+\frac{A}{\rho}+\frac{B}{\Delta} E^{\varepsilon_{f}}
$$

This function is defined in the interval $\left[E_{h}^{*}, E_{H}\right]$. Besides that, the function that defines the inactive firm value is identical to the last proof and still given by (A.10), but now it is defined over the interval $\left[0, E_{h}^{*}\right]$. The frontier conditions are also the same, however, now the purpose is to find the exchange rate critical value that makes optimal call the investment option under a superior limit $E_{H}$. They are:

$$
\begin{aligned}
& F_{0}\left(E_{h}^{*}\right)=F\left(E_{h}^{*}\right)-I \\
& F_{0}^{\prime}\left(E_{h}^{*}\right)=F^{\prime}\left(E_{h}^{*}\right)
\end{aligned}
$$

Using this condition on the previous functions generates the following exchange rate critical value:

$$
E_{h}^{*}=\left[\frac{\Delta \lambda_{1}}{B\left(\varepsilon_{f}-\lambda_{1}\right)}\left(\frac{A}{\rho}-I\right)\right]^{\frac{1}{\varepsilon_{f}}}
$$

\section{Proof of Proposition 4}

When there is an inferior limit given by $E_{L}>0$, it is not necessary to use the $F(0)=0$ restriction to rule out speculative bubbles, since the exchange rate already has a positive inferior limit. But, the overvaluation restriction remains valid. Thus, the active firm value will be given by:

$$
F(E)=k_{2} E^{-\lambda_{2}}+\frac{A}{\rho}+\frac{B}{\Delta} E^{\varepsilon_{f}}
$$


Where $\lambda_{2}>0$ is a root of the indicial equation and $k_{2}$ is a constant to be determinated. As before, the inferior limit acts like a reflection barrier, meaning that $F^{\prime}\left(E_{L}\right)=0$. Substituting this restriction in (A.19) generates the following equations:

$$
\begin{aligned}
& k_{2}=\left(\frac{B \varepsilon_{f} E_{L}^{\varepsilon_{f}+\lambda_{2}}}{\Delta \lambda_{2}}\right)>0 \\
& F(E)=\left(\frac{B \varepsilon_{f} E_{L}^{\varepsilon_{f}+\lambda_{2}}}{\Delta \lambda_{2}}\right) E^{-\lambda_{2}}+\frac{A}{\rho}+\frac{B}{\Delta} E^{\varepsilon_{f}}
\end{aligned}
$$

So, it is possible to observe that this function is defined over the interval $\left[E_{l}^{*}, \infty\right]$ and that the exclusion of exchange rates values lower than $E_{L}$ raises the active firm values. The inactive firm value will be also altered. It uses the overvaluation restriction and has the following form:

$$
F_{0}(E)=c_{2} E^{-\lambda_{2}}
$$

Where $\lambda_{2}>0$. This function is defined over the interval $\left[E_{L}, E_{l}^{*}\right]$. Thus, in a model with an inferior limit, the frontier conditions are:

$$
\begin{aligned}
& F_{0}\left(E_{l}^{*}\right)=F\left(E_{l}^{*}\right)-I \\
& F_{0}{ }^{\prime}\left(E_{l}^{*}\right)=F^{\prime}\left(E_{l}^{*}\right)
\end{aligned}
$$

Substituting the functions in these conditions generates the follow exchange rate critical value:

$$
E_{l}^{*}=\left[\frac{\Delta \lambda_{2}}{B\left(\varepsilon_{f}+\lambda_{2}\right)}\left(I-\frac{A}{\rho}\right)\right]^{\frac{1}{\varepsilon_{f}}}
$$

\section{The critical value under crawling peg regime}

The construction of this problem needs the definition of the active firm value which is given by:

$$
F(E)=k_{1} E^{\lambda_{1}}+k_{2} E^{-\lambda_{2}}+\frac{A}{\rho}+\frac{B}{\Delta} E^{\varepsilon_{f}}
$$


Where $\lambda_{1}$ and $\lambda_{2}>0, k_{1}$ and $k_{2}$ are constants to be determined. In this case, speculative bubbles have already been ruled out and none of the constants can be eliminated from an active firm's value, since this function is inferior and superior limited. It is defined in the interval $\left[E_{c p}^{*}, E_{H}\right]$. The constants can be obtained using the barrier restrictions $F^{\prime}\left(E_{H}\right)=F^{\prime}\left(E_{L}\right)=0$. It generates the following values:

$$
\begin{aligned}
& k_{1}=\left(\frac{B \varepsilon_{f}}{\Delta \lambda_{1}}\right) \frac{E_{H}^{\varepsilon_{f}}\left[\left(\lambda_{1}-1\right)\left(\frac{E_{L}}{E_{H}}\right)^{\lambda_{1}}+\left(\frac{E_{H}}{E_{L}}\right)^{\lambda_{2}}\right]-\lambda_{1} E_{L}^{\varepsilon_{f}}}{E_{L}^{\lambda_{1}}-E_{H}^{\lambda_{1}}\left(\frac{E_{H}}{E_{L}}\right)^{\lambda_{2}}}<0 \\
& k_{2}=\left(\frac{B \varepsilon_{f}}{\Delta \lambda_{2}}\right) \frac{E_{H}^{\lambda_{2}}\left(E_{H}^{\varepsilon_{f}} E_{L}^{\lambda_{1}}-E_{L}^{\varepsilon_{f}} E_{H}^{\lambda_{1}}\right)}{E_{L}^{\lambda_{1}}-E_{H}^{\lambda_{1}}\left(\frac{E_{H}}{E_{L}}\right)^{\lambda_{2}}}>0
\end{aligned}
$$

So, the constant $k_{1}$ reduces the active firm value while the constant $k_{2}$ increases it. Substituting (A.26) in (A.25) results in the following active firm value:

$F(E)=\left[\left(\frac{B \varepsilon_{f}}{\Delta \lambda_{1}}\right) \frac{E_{H}^{\varepsilon_{f}}\left[\left(\lambda_{1}-1\right)\left(\frac{E_{L}}{E_{H}}\right)^{\lambda_{1}}+\left(\frac{E_{H}}{E_{L}}\right)^{\lambda_{2}}\right]-\lambda_{1} E_{L}^{\varepsilon_{f}}}{E_{L}^{\lambda_{1}}-E_{H}^{\lambda_{1}}\left(\frac{E_{H}}{E_{L}}\right)^{\lambda_{2}}}\right] E^{\lambda_{1}}+\left[\left(\frac{B \varepsilon_{f}}{\Delta \lambda_{2}} \frac{E_{H}^{\lambda_{2}}\left(E_{H}^{\varepsilon_{f}} E_{L}^{\lambda_{1}}-E_{L}^{\varepsilon_{f}} E_{H}^{\lambda_{1}}\right)}{E_{L}^{\lambda_{1}}-E_{H}^{\lambda_{1}}\left(\frac{E_{H}}{E_{L}}\right)^{\lambda_{2}}}\right] E^{-\lambda_{2}}+\frac{A}{\rho}+\frac{B}{\Delta} E^{\varepsilon_{f}}\right.$

Note that the net effect of bands inclusion in active firm value is dependent from the model parameters, especially the band limits $\left(E_{L}\right.$, $\left.E_{H}\right)$, the indicial equation roots $\left(\lambda_{1}, \lambda_{2}\right)$ and foreign market demand elasticity $\left(\varepsilon_{f}\right)$. The inactive firm value will be given by:

$$
F_{0}(E)=c_{2} E^{-\lambda_{2}}
$$

Where $c_{2}$ is a constant to be determined. The inactive firm value is also bound, since it is defined over the interval $\left[E_{L}, E_{c p}^{*}\right]$. Thus, like the inferior limit model, the speculative bubbles possibility is eliminated using the overvaluation restriction. So, besides the two barriers restrictions, the problem has more two frontier conditions given by:

$$
\begin{aligned}
& F_{0}\left(E_{c p}^{*}\right)=F\left(E_{c p}^{*}\right)-I \\
& F_{0}{ }^{\prime}\left(E_{c p}^{*}\right)=F^{\prime}\left(E_{c p}^{*}\right)
\end{aligned}
$$


Where $E_{c p}^{*}$ denotes the critical value for the nominal exchange under a crawling peg regime, which calls the investment option optimal. Thus, there are two non-linear equations with two unknown values that remain to be determined, $c_{1}$ and $E_{c p}^{*}$.

This system cannot be solved analytically and an alternative way to obtain solutions should be used. These values are obtained through numerical methods, since the problem can be summarized to find zeros of a polynomial equation. 